\title{
6 Peirce and Sellars on Nonconceptual Content
}

\author{
Catherine Legg
}

How do sensory experiences (or qualia) manage to combine with concepts to produce the rich human thinking we all enjoy? Obviously it happens, as for example when I form a perception of a yellow chair in which an experience of yellowness and a concept of 'chairhood' both participate. But the question of how exactly it happens seems worthy of philosophical reflection in that these two things seem crucially different from one another. They differ first in that sensory experiences enjoy a certain felt immediacy or presence (that particular yellow, which I may or may not be able to express in words), while concepts participate in wide-ranging logical relationships across an entire space of reasons (for instance that the yellow chair, qua chair, is not identical with any single electron in the Universe: actual or even potential). But the puzzle extends even further-sensory experiences and concepts seem possessed of incompatible properties in that the former seem to enjoy a kind of 'private' infallibility, while judgments constructed from concepts are clearly truth-apt and fallible. Previously I have explicated this 'Experience-Truth Gap' as follows:

On the one hand, my perceptions are suffused with immediately felt experience (for instance, the juicy, sweet 'cherryness' of a cherry I am biting into), which it seems that in some important sense 'no-one can take away from me.' Thus the nature of our sensory feels appears to enjoy some degree of infallibility. ('Even if that cherry was a total hallucination, I can't be wrong about how it tasted to me.') On the other hand, much of the point of perception seems to be to enable us to endorse new propositions about the world that are truth-apt. ('This cherry is delicious! But is it really a cherry, or rather a small plum?') In this regard our perceptions seem perfectly fallible. This is all rather confusing.

(Legg 2017, 42-3)

Insofar as this disparity does represent a tension in philosophy of perception, it obviously bleeds profusely into epistemology more generally. 


\section{Catherine Legg}

Sellars was far-sighted in his day in noting and highlighting this tension. He thought (rightly, I believe) that it was being quite overlooked by his empiricist contemporaries, including noted logical positivists such as Carnap and Ayer, leading to "perplexities ... . when one tries to think [empiricism] through" (Sellars 1997, $\$ 7,25$ ). He diagnosed the problem as lying with the peculiar infallibility attributed to sensory experience. He famously dubbed this the Myth of the Given. But the Myth's exact legacy, and in what way philosophers should best avoid it, if they should, is still being determined.

Important work here has been done by Sellars's students-notably John McDowell. In McDowell (2004a, 2004b), he explored how sensibility and the understanding (or more poetically, following Kant, receptivity and spontaneity) combine to create human cognition that is subject to logical appraisal. In seeking to reconcile these two faculties, as he understood them, McDowell sought a middle way between the bald naturalism that he argued results from over-reliance on receptivity and the 'frictionless coherentism' that he argued results from over-reliance on spontaneity. He argued that Sellars's identification of the Myth led him to excessively deprecate the contribution of sensory experience to human cognition, developing instead a purely conceptual epistemology (i.e., an inferentialism) which in McDowell's view falls into frictionless coherentism. Thus, McDowell charges Sellars with failing to account for the primal confrontation between mind and world which constitutes genuine perception, and thus knowledge. But since then, McDowell has not been entirely satisfied with his appraisal of Sellars. In Having the World in View he has returned to the same ground and offered a somewhat different take, which I shall discuss below.

Robert Brandom has also done much to bring these issues to light (Brandom 1994, 2000, 2007). His dogged defense of an inferentialist as opposed to a representationalist account of content-according to which the valid inferences into which a given proposition may enter constitute its entire meaning - has been (among other things) an attempt to rehabilitate the conceptual, and thus rationalism, against the unreflective empiricism of most analytic philosophy. The systematicity he has managed to achieve in working out his new inferentialist doctrine has brought fascinating new currents to mainstream philosophy. But it has also dismayed a number of Brandom's pragmatist peers, who feel that he has swung so far towards rationalism that he has landed in intellectualism. ${ }^{1}$ Brandom's analytic pragmatism has been charged with an 'experience problem.' For instance, Paul Redding has argued that Brandom fails to recognize the way in which by means of perception we form beliefs de re as well as de dicto. Giving the example of himself wearing a blue tie, Redding claims that perceptual experience will most likely show the tie to be some particular shade of blue which, although it can be more and more precisely described, can never be fully captured in concepts, and thus in propositional form:

Perceptual experience, it might be said, is more fine-grained than what is actually captured by any general concept ... this feature of perceptual 
experience does not seem to be captured in the de dicto expression: the semantics of a de dicto expression depends simply on whether the proposition is true or false. The way in which my tie makes the proposition true or false drops from consideration altogether.

(Redding 2014, 668)

In other words, perception seems to be a belief-forming mechanism characterized by a kind of direct confrontation between mind and world which, in its felt immediacy and the bottomless determinacy of its detail, differs crucially from merely understanding that the proposition "Paul Redding is wearing a blue tie" is true.

Admittedly, Brandom has tried to clear some space in his epistemology for sense-experience. He acknowledges that for apparently simple pure qualia such as the color red, it seems counterintuitive to account for their meaning solely in terms of inferences licensed both 'upstream' (in propositions from which it follows that something is red) and 'downstream' (in propositions which follow from something being red). What would such inferences be? Didn't Frank Jackson show us with his famous 'Black and White Mary' thought experiment (Jackson 1982) that it is conceivable that a person might be able to license all valid red-related inferences, yet still not understand the true meaning of red-the unique and distinctive experience of seeing it? ${ }^{2}$ For such concepts, then, Brandom makes an exception to his inferentialism, allowing their meaning to be at least partly specified by simple (i.e., mere stimulus-response) 'reports' on the part of relevant sensory mechanisms: in Articulating Reasons, he calls this the color red's "noninferential circumstances of appropriate application" (Brandom 2000, 21). This concession to qualia is what makes Brandom a strong rather than a hyperinferentialist. He describes himself as thereby offering a 'two-ply' theory of perception, which weaves together an experiential and an inferential strand, thereby showing itself:

The product of two distinguishable sorts of abilities: the capacity reliably to discriminate behaviorally between different sorts of stimuli, and the capacity to take up a position in the game of giving and asking for reasons.

(Brandom 2002, 349)

But in order that his first 'strand' avoid the Myth of the Given, Brandom qualifies that "even such noninferential reports must be inferentially articulated" (Brandom 2000, 47). This qualification is what makes Brandom a strong rather than a weak inferentialist. How can a noninferential report be inferentially articulated? Brandom gives the example of a culture where "white is the colour of death and things associated with death are to be shunned or avoided." Here the concept white "can be understood to be inferential in a broad sense, even when the items connected are not themselves sentential” (Brandom 1994, 658). 


\section{Catherine Legg}

To sum up this section, sensory experience and conceptual understanding seem prima facie quite different things. It would be difficult to deny that sensory experience plays a vital role in perception-yet where the border exists between it and the conceptual, and how they manage to combine to produce thought, is still at this point rather mysterious. One way of posing these issues is as a discussion of so-called nonconceptual content. If we admit that experience does play a vital role in perception, should we not then understand perception as delivering nonconceptual as well as conceptual content? Lively debates on this matter currently abound in mainstream philosophy (e.g., Peacocke 1992, 1998; Bermúdez 1995; Speaks 2005).

Here I wish to bring Charles Peirce to the table as I believe he has ideas to offer these characteristically 'Pittsburgh School' debates that are highly congenial, yet to date largely unexplored. In prior work I have situated Peirce with respect to Brandom's inferentialism, arguing that Peirce is a hyperinferentialist due to his early (1860s) unequivocal rejection of intuition in epistemology, claiming instead that all thought is in signs. I argued that Peirce works out an inferentialist account even of qualia such as red through naturalistic arguments which challenge the self-certainty of introspection, showing that we are not able to tell by intuition whether a thought is an intuition or an inference, and (what comes to the same thing) sketching a model of our sensory capacities in which many inferences occur below conscious awareness (Legg 2008).

In later papers (Legg 2014, 2017) I have begun to explore Peirce's more mature commentary on these issues, in a full-fledged theory of perception that he presented around 1902. Here Peirce accords a more explicit and direct role to experience in an entirely preconceptual percept, but this is overlaid with a level of perceptual judgment which (I believe) corresponds to Sellars's space of reasons. What is most interesting here is the relationship Peirce charts between percept and perceptual judgment: the latter does not describe, nor is it justified by the former, rather, it indexes it-how will be explained below.

As I have not yet related Peirce's theory of perception specifically to Sellars-who might justly be described as 'inferentialism's original fount'this is my task here. I will begin by explicating Sellars's classic account of the Myth of the Given, and how to avoid it, in Empiricism and Philosophy of Mind (henceforth: EPM). Then I will consider McDowell's most recent (2009) critique of Sellars's account of perception, in order to sharpen our understanding. Then I will present Peirce's mature theory of perception, and finally relate it to Sellars's view, thereby showing how Sellars is able to avoid McDowell's critique of him. We will discover a remarkable amount in common between Sellars and Peirce on perception. This includes a direct realism that is rare in modern philosophy, paired somewhat paradoxically with a crucial role played by diachronic habit as against Cartesian ideals of immediate apprehension. (It will, moreover, be explained why the paradox is only 
apparent.). These two features lead to an overall critical common-sensist account of rationality, which Sellars counterposes to the mainstream foundationalism of his day, and which I shall argue is also very Peircean. But I shall begin by reviewing the famous Myth of the Given, and its dire warnings.

\section{The Myth of the Given}

The Myth of the Given has arguably itself attained somewhat mythical status in certain philosophical circles as simultaneously deeply important not to commit, yet difficult to understand. But the underlying idea is relatively straightforward. Myth-makers purport to analyze "epistemic facts" into “non-epistemic facts” (Sellars 1997, $\$ 5,19$ ), which doesn't work.

As noted, Sellars diagnoses the Myth as most pressingly a problem for classical empiricism. ${ }^{3}$ Although the claim that all knowledge derives from experience is defining for empiricism, Sellars asserts that a crucial ambiguity infects precisely that concept. By Sellars's day, experience was frequently being referred to as sense-data, and he adopts this terminology for purposes of critical scrutiny. Famously, he claims that the concept of sense-data confuses two importantly different notions. The first is: "1) The idea that there are inner episodes-e.g., sensations of red ... which can occur to human beings . . . without any prior process of learning or concept formation." This is a purely causal notion of bodily impingement which accords, for instance, with Hume's official account of an impression. The second notion is: "2) The idea that there are certain inner episodes which are . . . noninferential knowings that certain items are, for example red . . . and that these episodes are the necessary conditions of empirical knowledge as providing the evidence for all other empirical propositions" (Sellars 1997, $\mathbb{} 7$, 21-2). This is what Hume's notion of an impression actually needs to be in order for it to play the role that Hume accords it in his epistemology.

Why is this confusion pernicious? First and foremost, it is intellectually dishonest. Sense-data notion 2) may be a basis for an epistemologyalthough Sellars's sympathies ultimately do not lie with this variety of foundationalism (Sellars 1997, $\mathbb{3} 38,78$ ), but it is not non-epistemic, as 'knowings' occur in it unreduced. Only sense-data notion 1) actually presents a non-epistemic analysans, but it is no proper basis for an epistemology. Sellars's argument for this is lengthy and subtle, but essentially he argues that sense-data so understood cannot play an appropriate justificatory role with regard to our knowledge. It is simply not helpful to state that because $\mathrm{X}$ 'looks' red to $\mathrm{P}, \mathrm{P}$ is justified in believing that $\mathrm{X}$ is red, and therefore (if $\mathrm{X}$ is indeed red) ' $\mathrm{P}$ knows that $\mathrm{X}$ is red.'

Sellars's argument against this philosophical move carefully disentangles the way that 'looks talk' is actually used. Aided by a legendary thoughtexperiment about a tie shop with confusing lighting, he notes that the statement, 'This tie looks green' only arises when it is known that surrounding 


\section{Catherine Legg}

conditions are liable to make a tie appear green when it is not really green (e.g., if one takes the tie outside into sunlight). Otherwise, all parties involved in the situation will simply state, 'This tie is green.' So, rather than the statement ' $\mathrm{X}$ looks green' routinely offering epistemic support for the knowledge ' $\mathrm{X}$ is green,' the statement is used precisely to signal an appearance that one has reason to believe may well differ from reality, due to: (i) extensive background knowledge of standard conditions for something to look the color that it is, (ii) knowledge that those conditions are not met in this case. And so, when it comes to epistemic priority, ' $\mathrm{X}$ looks green' is parasitic on ' $\mathrm{X}$ is green,' rather than the reverse (Sellars 1997, $\mathbb{\$} 18,43$ ). Such logical dependencies of color-concepts on extensive background knowledge of suitable conditions in which to view them are anathema to traditional empiricism's logical atomism, according to which something's 'looking green' might be the only thought one ever has (Sellars 1997, $\$ 19,44$ ). Lest it be argued that the particular contingent tie shop scenario is a very slender reed to support the strong conclusion that claims of the form ' $\mathrm{X}$ looks $\mathrm{P}$ ' are parasitic on claims of the form ' $\mathrm{X}$ is $\mathrm{P}$ ' in all circumstances, Sellars develops further strands to his argument. These include trying to imagine a community that uses 'is talk' but not 'looks talk'-which he argues is conceivable-and trying to imagine a community that uses the latter but not the former-which he argues is not. ${ }^{4}$

How does Sellars propose to avoid the Myth? He counterposes to his contemporaries' unreflective empiricism a rationalism that holds that there is no direct or intrinsic characterization of immediate experience (Sellars 1997, $\$ 25,57)$. Nor is it right, he argues, to build a systematic account whereby immediate experience plays a 'self-authenticating' role for our knowledge. Rather than building our epistemology around the search for ideal prior conditions for knowledge-formation in the individual, we should understand knowledge-formation as a group endeavor in which critical scrutiny can be applied by anyone, anywhere, at any time:

the correctness of a report does not have to be construed as the rightness of an action. A report can be correct as being an instance of a general mode of behavior which, in a given linguistic community, it is reasonable to sanction and support.

(Sellars 1997, \$35, 74)

Relatedly,

in characterizing an episode or state as that of knowing, we are not giving an empirical description of that episode or state; we are placing it in the logical space of reasons, of justifying and being able to justify what one says.

(Sellars 1997, \$36, 76) 
Yet isn't it counterintuitive (so to speak!) to hold that there is no direct or intrinsic characterization of immediate experience? Sellars does not deny that sensations are present, and that they play a causal role in our perception:

One can certainly admit that the tie between 'red' and red physical objects . . . is causally mediated by sensations of red, without being committed to the mistaken idea that it is 'really' sensations of red, rather than red physical objects, which are the primary denotation of the word 'red.'

(Sellars 1997, $\$ 29,64)$

So is Sellars committed to nonconceptual content or not? We turn now to McDowell for further enlightenment.

\section{McDowell on Sellars: Rational Capacities Permeate Our Perception (But Not Rational Judgments)}

We noted that in Mind and World McDowell charges Sellars with an excessively rationalist coherentism. In his 1997 Woodbridge lectures, published in 2009 as Having the World in View, McDowell adopts a more nuanced evaluation of his great teacher. Much of this discussion departs from a certain statement that Sellars makes when rejecting foundationalism in epistemology as standardly construed. Sellars remarks that although he does not wish to say that empirical knowledge has no foundation, the metaphor of 'foundation' is misleading, because:

it keeps us from seeing that if there is a logical dimension in which other empirical propositions rest on observation reports, there is another logical dimension in which the latter rest on the former.

(Sellars 1997, \$38, 78)

This second logical dimension, which runs to observation statements from other empirical propositions, was evident in the tie shop example, where the salesperson takes the tie outside in the sun and observes 'This tie is blue' not only because he is seeing blueness, but also because he knows that sunlight constitutes reliable conditions for detecting blueness.

In order to further explicate the two-way nature of this logical relationship, McDowell develops the metaphor of a line demarcating Sellars's allimportant "logical space of reasons":

Sellars' thesis is that the conceptual apparatus we employ when we place things in the logical space of reasons is irreducible to any conceptual apparatus that does not serve to place things in the logical space of reasons. So the master thought [of EPM] as it were draws a line; above 


\section{Catherine Legg}

the line are placings in the logical space of reasons, and below it are characterizations that do not do that.

(McDowell 2009, 5)

Now our question concerning whether there is any nonconceptual content can be put by asking: Does anything lie 'below the line' in Sellars's account of perception? And if so, what role does it play?

McDowell begins by noting that Sellars seems to straightforwardly acknowledge some 'below the line' contribution to perception towards the end of EPM (X onwards), where he vindicates a role for 'inner episodes' in order to distinguish himself from behaviorists such as Skinner. But what contribution, exactly, is made by these inner episodes? One might suppose that it is some kind of phenomenology that renders (for instance) my perception that Redding's tie is blue characteristically visual. But McDowell argues that the visual blueness of Redding's tie occurs 'above the line' (McDowell $2009,14)$. What lies above the line is not "phenomenologically colourless." So why posit anything below the line? We noted earlier that Sellars admits that "the tie between 'red' and red physical objects . . . is causally mediated by sensations of red." McDowell considers the possibility that such posited sensations are needed to scientifically explain similarities between blue things and blue hallucinations (McDowell 2009, 15). But why should these 'below the line' entities be understood as sensations? Why not go straight to a physiological story to explain blue hallucinations? McDowell remarks, "The sensations look like idle wheels" (McDowell 2009, 16).

McDowell goes on to suggest that in Sellars's later work, sensations are posited as less of a scientific explanation and more of a transcendental argument establishing that our knowledge is objective through "having the world in view." Sensations are "directed towards showing our entitlement to conceive subjective occurrences as possessing objective purport" (McDowell 2009, 17). In this view, sensations are not, to use Kantian language, apperceived (i.e., 'themselves visible' in perception). Nevertheless it is helpful to say that they perform a "guiding function" for "the flow of one's conceptual representations" (McDowell 2009, 22). What does this mean? Using a probably too-crude illustration, one might say that when one directly perceives a cat, one experiences a 'flow of cat-related concepts' (whiskers, tail, fur and so forth) which together fall into a certain overall 'shape', which constitutes a non-concept-involving, and therefore below the line, impression of a cat.

Let us pause and note that what is described here might be understood as a form of indexicality. This is an interesting thought which will be addressed again shortly. For McDowell, though, this Sellarsian 'guiding' and 'shaping' which cannot be apperceived and is in principle unconceptualizable is just too mysterian and unhelpful. (He even claims that, ironically, it itself is redolent of the Myth of the Given.) He closes his volume with a chapter designed to finally sort out the Myth. Here he claims that "intuitional 
content" is still conceptual (and thus above the line) although it is "not discursive content at all" (McDowell 2009, 270). The model for this is "having something in view"-for instance a red cube.

McDowell claims that having a red cube in view "is complete in itself" (McDowell 2009, 270). It is not, as it stands, a judgment in propositional form (such as 'This cube is red'). Nevertheless, it draws on 'conceptual capacities'-our understanding of redness and cubehood, and to that extent it can be understood as having "judgment-shaped contents" when viewed in the appropriate light-that is, by a language user from within their language (McDowell 2009, 35). Yet at the same time as McDowell claims that the perception draws on conceptual capacities, he claims that the concepts themselves do not 'figure' in the experience itself. He claims that if he and another person view a particular bird which McDowell knows to be a cardinal and the other does not, it is not the case that the concept 'cardinal' features in his perception and not the other person's. As both persons have the same bird in view, their experience has the same intuitive content (McDowell 2009, 259).

This complex, multimodal view is how McDowell explicates Kant's difficult notion of an 'intuition.' He claims that this undermines Sellars's transcendental argument which posits 'manifolds of sheer receptivity' (below the line) to secure objectivity in our knowledge by providing an 'external constraint' on our thinking. McDowell claims that, by contrast, in his understanding of perception the only external constraint required is "objects themselves . . . becoming immediately present" (McDowell 2009, 39 ), along with whatever judgment-shaped properties users of relevant languages are able to recognize. To sum up, then, McDowell argues against Sellars that sense-experience and understanding are importantly different, and yet in perception nothing occurs below the line and there is no nonconceptual content.

This determination has seemed to a number of philosophers to be disappointingly ad hoc in its separation (albeit somewhat equivocal and confusing) of perception from judgment, where one had hoped for an account which would explain the seamless continuity between them. What does it mean to claim that a perception is conceptual if it is not at all discursive? ${ }^{5}$ If having a red cube in view does not in itself involve judging that the cube is red, how is it that we $d o$ come to judge that the cube is red? ${ }^{6}$ There is also arguably an opportunity missed here to develop a coordinated causal and rational account of the contribution of sensation to perception-which is precisely what we shall now explore.

\section{Peirce's Mature Theory of Perception}

Interestingly, Peirce may also be understood as offering a 'two-ply' theory of perception. He also separates immediate experience, which he calls the percept, from truth-apt propositions derived from that experience, which 


\section{Catherine Legg}

he calls the perceptual judgment. Peirce's realm of perceptual judgment thus corresponds nicely to Sellars's space of reasons. Moreover, Peirce takes a position on the autonomy of the space of reasons which is very Sellarsian, while arguing against an antecedent of the empiricism of Carnap and Ayer which he finds in the philosophy of John Venn:

Mr. Venn belongs to a school which considers the logical process as starting at the percepts, if not at impressions of sense. . . . But I maintain that logical criticism cannot go behind ... the first judgments which we make concerning percepts.

(Peirce CP, 7.198)

Peirce's stated reason for this claim, though, focuses less on the possibility of justification than criticism. He writes that criticism never pertains to a perception taken on its own, but only in juxtaposition with further facts, which requires that the whole be propositionally formulated in order to generate a contradiction:

I look at an object and think that it seems white. That is my judgment of the object perceived ... [it] does not, in itself, call for any explanation. On the contrary, it can only do that when it has been connected with other facts which taken by themselves would justify an expectation of the contrary of this fact. For example, if we should find that this object which seemed white, in the first place was white, and then that it was a crow, and finally that all the crows known were black.

(Peirce CP, 7.198)

Peirce notes that by contrast the percept, as it is outside of the space of reasons, strictly cannot be described, in a manner interestingly reminiscent of Travis (2004):

I recognize that there is a percept or flow of percepts very different from anything I can describe or think. What precisely that is I cannot even tell myself. ... I am forced to content myself not with the fleeting percepts, but with the crude and possibly erroneous thoughts, or selfinformations, of what the percepts were.

(Peirce CP, 2.141)

The percept cannot be described as it is singular. It "is a single event happening hic et nunc," which "cannot be generalized without losing its essential character" (Peirce CP, 2.146). To put the same point another way, the percept cannot be described as it is fully determinate. Peirce at one point likens the perceptual judgment to "the printed letters in a book, where a Madonna of Murillo is described," and the percept to the exquisite picture itself (Peirce CP, 5.54). Here we see Peirce articulating Redding's insight 
that perception differs from mere de dicto judgment in the 'indescribable' quantity of information it presents. (This similarity is not surprising since both thinkers share deep Kantian roots.)

At this point, though, one might wonder: why does Peirce's percept not grievously recreate the Myth of the Given, ${ }^{7}$ if it is some kind of nonepistemic faculty that is posited at the root of all perception? But we shall see that the percept does not stand in a justificatory relation to the perceptual judgment. So how do the percept and the perceptual judgment relate to one another, as they must if Peirce is to present a coherent theory of perception? Not in the way that might seem intuitively obvious-and the way that empiricism has traditionally supposed-according to which the perceptual judgment describes or copies the percept (as for instance British Empiricist Hume claimed that all our ideas form as copies of impressions). ${ }^{8}$ Peirce also explains why the percept cannot justify the perceptual judgment: as it is not in propositional form (not even close), it cannot serve as any kind of premise from which the perceptual judgment is concluded. Instead, Peirce claims, "there is no relation between the predicate of the perceptual judgment and the sensational element of the percept, except forceful connections" (Peirce $\mathrm{CP}, 7.634)$. In other words: the role of the perceptual judgement is solely to index the percept. ${ }^{9}$ This simply means that the percept causes the perceptual judgment whilst not providing any of its content.

We earlier saw McDowell consider and reject the idea of positing something that performs a 'guiding function' for a flow of conceptual representations in perception, while not being itself apperceived. Peirce's percept performs precisely this role. So although the percept was aligned above with 'immediate experience,' this should not be understood as immediate experience as sense-data, but immediate experience as direct contact with an object. Thus, this is a form of Reidian direct realism (which in contemporary philosophy of perception is now frequently dubbed relationalism). ${ }^{10}$

Perception is a process that takes place across time, though, and over time our constant causal triggers from percept to perceptual judgment gradually become enmeshed in an ever more smooth and predictable network of habits of association between certain kinds of percepts and certain kinds of perceptual judgments. How this occurs is best explicated in the broader framework of Peirce's pragmatist theory of meaning, whereby belief consists in nothing but habits of expecting certain experiences in certain circumstances, and acting to bring about desired future experiences in that light. In short, our evolutionary legacy ensures that from birth our percepts produce "direct and uncontrollable interpretations" (Peirce CP, 7.648). These are trained, guided and corrected by our language-community until we produce perceptual judgments that are appropriate to our circumstances. For this educative process, the nature of the percepts lying behind these judgments matters not, as only the latter are publically accessible to our teachers. ${ }^{11}$ Crucially, this repetition of (noninferential) causal triggers until they become (inferential) habits of association is how concepts are built in 


\section{0}

Catherine Legg

Peirce's philosophy. There is no other (dualist) 'mind-stuff' from which concepts are made. ${ }^{12}$ This is the great elegance of Peirce's view, and its prospects for underpinning a thoroughly naturalistic philosophy of mind.

One further feature of Peirce's account of how percept and perceptual judgment combine requires remarking on before I turn to Sellars. Despite their great difference from one another, the presence of stable habits of expectation and action enables the two to interlock in a process of mutual modification which is entirely two-way. Peirce puts it like this:

I have no means whatever of criticizing, correcting or recomparing [percepts], except that I can collect new perceptual facts relating to new percepts, and on that basis may infer that there must have been some error in the former reports, or on the other hand I may in this way persuade myself that the former reports were true.

(Peirce CP, 2.141)

This means that strictly speaking there is no way that the percept is, in and of itself (or 'in view'). The percept only exists as interpreted-and thus potentially reinterpreted—by the perceptual judgment: ${ }^{13}$

Now let us take up the perceptual judgment 'This wafer looks red.' It takes some time to write this sentence, to utter it, or even to think it. It must refer to the state of the percept at the time that it, the judgment, began to be made. But the judgment does not exist until it is completely made. It thus only refers to a memory of the past; and all memory is possibly fallible and subject to criticism and control. The judgment, then, can only mean that so far as the character of the percept can ever be ascertained, it will be ascertained that the wafer looked red.

(Peirce CP, 5.544)

Here Peirce differs crucially from McDowell. We saw that McDowell claimed that where two people view a cardinal, one of whom has the concept 'cardinal' and the other not, they can have the very same experience. In this sense, McDowell retains a preconceptual 'space of experience,' but for Peirce there is no such space. In that sense McDowell's 'line' metaphor is potentially misleading: more on this as follows.

\section{Sellars Viewed in the Light of Peirce}

Peirce's Reidean direct realism, which captures the de re dimension of perception highlighted by Redding, is arguably the best way of making sense of what Sellars means when he speaks in EPM of sensations performing a 'guiding function' for a flow of conceptual representations while not themselves being apperceived. In a later extended discussion of phenomenalism, 
Sellars is even more explicit about this. In a section entitled "Direct Realism: Causal vs Epistemic Mediation," he writes:

the direct perception of physical objects is mediated by the occurrence of sense impressions which latter are, in themselves, thoroughly noncognitive. Furthermore, this mediation is causal rather than epistemic. Sense impressions do not mediate by virtue of being known.

(Sellars 1963, 91)

Ironically this kind of direct realism sounds a great deal like how McDowell says he wants to understand "having the world in view"-solely as "objects themselves . . . becoming immediately present" (McDowell 2009, 39). How McDowell managed to reject Sellars's proffered indexicality by confusing it with a kind of transcendental phenomenology is difficult to understand. ${ }^{14}$ I would guess that a significant role is here played by a certain ambiguity in the technical philosophical term impression: between an 'experience' (phenomenological) of a sensation and an 'experience' (transactional or indexical) of an object. ${ }^{15}$ Sellars is arguably thinking of the latter, yet McDowell cannot help reading the former. This ambiguity-and the resulting confusion generated in philosophy-goes back to the early modern philosophy's 'veil of ideas ${ }^{16}$ _ indeed is arguably created by it.

Sellars also echoes Peirce's focus on habit. He shows keen awareness of a diachronic dimension to perception, and makes it crucial to his attack on the Myth of the Given, when he criticizes classical empiricists as follows:

they have taken givennness to be a fact that presupposes no learning, no forming of associations, no setting up of stimulus-response connections.

(Sellars 1997, \$6, 20)

A third point of confluence between Sellars and Peirce arguably consists in some form of critical-common-sensism. In the discussion of phenomenalism cited above, Sellars not only claimed that the mediation of perception by sensations is causal not epistemic, he also claimed that realizing this constitutes a crucial step "towards an adequately critical direct realism" (Sellars 1963,90$).{ }^{17}$ Why? I would suggest, precisely to capture the two-way correction between percept and perceptual judgment we saw Peirce elaborating earlier. Ironically, by removing sensory experiences from the role of justifying our judgments, and rendering them instead preconceptual indices to a world independent of our minds, they become a much more powerful scaffold for self-correction as we go about our business of trying to know reality. This, I think, is the essence of the account of rationality that Sellars puts forward against the foundationalism that is still widely pervasive in mainstream philosophy: 


\section{Catherine Legg}

Empirical knowledge, like its sophisticated extension, science, is rational, not because it has a foundation, but because it is a self-correcting enterprise which can put any claim in jeopardy, though not all at once.

(Sellars 1997, $\$ 38,79$ )

With so much commonality now established between Sellars and Peirce, it is worth considering whether there are any important differences. One feature of Sellars's thought that comes instantly to mind is his psychological nominalism, whereas Peirce famously vows to oppose nominalism in all its forms. Yet Sellars defines psychological nominalism as the view that, "all awareness of sorts, resemblances, facts etc. . . . is a linguistic affair" (Sellars 1997, $\$ 29,63)$-in other words, general properties consist in 'mere words' (and their uses). In an interesting sense of this claim, I don't think that Peirce would disagree. ${ }^{18}$ I hope to investigate this matter more fully in a future study. A second potential major disagreement concerns the 'naturalizing of normativity.' We have noted that Peirce presents an elegant platform for this in holding that concepts, with their rich network of normative forces, are formed through the repetition of (noninferential) causal triggers until they become (inferential) habits of association. Sellars, on the other hand, famously separates the world's normative manifest image from a scientific image that he envisages to be purely descriptive. Yet whether such a separation is what Sellars most wants, or rather all that he feels he is able to have given the state of development of his own philosophy, is an interesting question. ${ }^{19}$ Although the separation is reinforced in McDowell's strong dualism between 'first' and 'second' nature, and Brandom's Hegelian counterposing of Natur and Geist, the fact that there is an ongoing dispute between this 'left-wing' camp of Sellars adherents, and 'right-wingers' such as Ruth Milikan and the Churchlands who emphasize Sellars's unflinching scientific realism, suggests that possibilities lie germinal in Sellars's texts for a more thoroughgoing and integrated naturalism.

\section{Conclusion}

The fact that we are beings who perceive means that our thinking is constrained by a world which, to the degree that it constrains us, it makes sense to describe as 'external.' As philosophers, it is tempting to wonder at what point in our encounter with this world are concepts 'put onto' what we experience? But we have now learned that just because preconceptual experience is part of the explanatory story of perception, doesn't mean it should be reified into a discrete component of perception (that is itself apperceived). Just this insight arguably constitutes a significant step forward from mainstream empiricism, and much current debate around the existence or otherwise of 'nonconceptual content.' Yet arguably all the Pittsburgh School players largely agree on this point-so what is the difference between them? 
We've seen that Brandom holds a two-ply theory of perception according to which we apperceive not only concepts whose meaning is fully inferential, but also noninferential (mere stimulus-response) sensory 'reports.' In this way, unlike Peirce, he attempts to put both strands 'above the line.' But by assigning such sensory reports their own, sui generis, explicitly noninferential category within the semantic space he arguably compromises his inferentialism.

By contrast, McDowell claims that perception is conceptual through and through, and to that degree arguably manages to achieve a hyperinferentialism. Yet he feels obliged to draw a distinction between 'intuitional' and 'discursive' content, in order to postulate (in the form of intuitional content) a brute synchronic encounter between mind and world-a 'having the world in view' - as the basis for all our knowledge, just as Kant taught. In one of the many ironic twists and turns which characterize these debates, I would claim that this posited brute synchronic encounter resembles sufficiently what Sellars called a "direct or intrinsic characterization of immediate experience" (Sellars 1997, $\$ 25,57$ ) to constitute yet another face of the Myth of the Given.

I would like to venture the same point in another way, as follows. Inferentialism should mean more than just that concepts are somehow present ('sitting there'!) in perception. (Is the concept cardinal 'in' one's perception of a cardinal, or is it not?) Please forgive me for remarking that that seems a very representationalist view of the inferential. Let us recall that concepts are the basic ingredients not of physical space but of a space of reasons. As such, their role-the whole point of their presence, if you will-is to reason: to be always poised to correct and reinterpret any previous thoughts, according to the logical relationships between them. So to the extent that McDowell is able to think thoughts about the cardinal qua cardinal that his companion is not, his perception of it is not the same. This essentially dynamic quality of the conceptual is, I would argue, the vital insight that classical pragmatism can bring to these debates. ${ }^{20}$

To sum up McDowell, then, his fundamental claim that he sees as distinguishing himself from Sellars-that in perception 'intuitional content' lies 'above the line' - is a mixture of incorrect and misconceived. First, if we understand intuition not as qualitative and (in that sense) phenomenological, but as indexical, and indexicality as preconceptual (as I have argued that we should), then we must see 'intuitional content' as a contradiction in terms. Second-and even more profoundly-we must cast a critical eye on 'the line.' This metaphor was used by Sellars himself, and is in some ways extremely helpful in enabling us to discuss what can be part of a space of reasons and what can not. Yet at the same time it is arguably not helpful insofar as it suggests that there might be a space 'containing' reasons, and a space 'containing' only something else. The connection between the conceptual and the indexical in our thinking is much more intimate than that. ${ }^{21}$ In 


\section{Catherine Legg}

fact, in Peirce's thought we have seen how it is possible to explain concepts as themselves created from congeries of indices that are sufficiently repetitious to fall into intelligible patterns.

We have seen that both Sellars and Peirce managed to combine both a rare direct realism and a diachronic account of perception such that there is no direct or intrinsic characterization of experience-all perception is interpretative. The combination of these two claims has frequently been viewed as contradictory. But it is not. As Haack clearly explains:

Perception is interpretative. But it is neither necessary nor desirable to take this to mean that perception is not of things and events around us, but of images.... It is both possible and plausible to take it as meaning, rather, that though perception is of the things around us, our perceptual beliefs involve explanatory filling-in of the often limited information afforded us by our perceptual interactions with those things.

$($ Haack 1994, 32) 22

Seeing astutely through this apparent paradox enabled Sellars to replace foundationalism with a critical common-sensism still largely untried in mainstream epistemology. But although Sellars was a devastating critic of the dominant empiricism of his day, his positive account is arguably not as clearly or thoroughly worked out as Peirce's account of meaning in terms of habit, embedded in a broader pragmatist theory of meaning (which was in turn embedded in an ambitious general theory of signs, but that is another story)—to show how hyper-inferentialism can be operationalized.

\section{Notes}

1 See, for instance, Koopman (2007), Levine (2012). A related critique, though not from a self-avowed pragmatist, is McDowell (2005).

2 For this point I am grateful to Dave Beisecker.

3 Although intriguingly he suggests that it is also a problem for a putatively later Wittgensteinian understanding of language in terms of rule-following that is triggered by circumstances of rule-application that are themselves understood to be 'given' (Sellars 1997, \$30, 64-5).

$4 \mathrm{I}$ am grateful to Yuri Cath for pressing me on this point.

5 It should be noted that Paul Redding makes an interesting attempt to explicate this in terms of Hegel's distinctive theory of judgment in Redding (2017).

6 For me, the matter is not fully clarified by McDowell claiming that when he judges that there is a red cube in front of him, "a conceptual capacity corresponding to 'red' and a conceptual capacity corresponding to 'cube' have to be exercised with a togetherness corresponding to the togetherness of 'red' and 'cube'; in 'There is a red cube in front of me'," and that this provides, "a partial specification of the function that gives unity to the various representations in an ostensible seeing that there is a red cube in front of me" (McDowell 2009, 31). What exactly is this 'function'? Which part of it is here being specified? And what is the other part? 
7 For first raising this point to me in 2014, and for other comments which improved this paper, I am grateful to Willem DeVries.

8 Could the relationship be rightly viewed as a 'noninferential report', in Brandom's sense? In my view this is an interesting question, worthy of a separate study.

9 One of the first Peirce scholars to clearly highlight this key point was Susan Haack—see, for instance, Haack (1994).

10 For an interesting recent paper tracing links between these debates, see Sant'Anna (forthcoming).

11 In this regard Forman (2007) gives a nice account of how although McDowell dismisses sensations as 'idle wheels' for explaining concurrent perception of an object, he misses the way in which they form a necessary condition for acquiring empirical concepts in the first place.

12 For a brilliant unpicking of how this works, and some of its profound consequences for philosophy of mind and epistemology, see Massecar (2012).

13 This point is extremely well explicated in (Rosenthal 2001). Similar revisionary potential has been posited in human agency, whereby narrativity confers upon our actions a 'trajectory-dependent property.' For instance if $\mathrm{X}$ happens, then it is true that I was in love with $\mathrm{M}$ at a given time, whereas if $\mathrm{Y}$ happens, it is false (Jones 2008, 271-5). Given that Peirce's is a pragmatist theory of perception, this convergence is arguably no coincidence.

14 As I understand it, essentially the same point is made in DeVries (2006). See also DeVries and Coates (2009), Macbeth (2009).

15 Levine puts the same point well by stating that in Sellars's view, "the cues that sensation provides are structural instead of qualitative" (Levine 2007, 65). Interestingly, this structural dimension to sensory causes arguably bestows on them an iconic, over and above the indexical function that has been the focus of this paper. I thank Vera Saller for pointing this out to me. It is difficult to say much explicitly about this iconicity as the percept is so inarticulable, but once again resonances with Sellars appear in that he famously (somewhat controversially) talked of 'picturing' - albeit between tokens of linguistic expressions and the world (and thus 'above the line').

16 This ambiguity was noted in the last section where it was remarked that 'immediate experience' may be understood both as 'sense-data' and as 'direct contact with an object.'

17 See also Sellars (1982).

18 For instance, Peirce writes, "the external world ... does not consist of existent objects merely, nor merely of these and their reactions; but on the contrary, its most important reals have the mode of being of what the nominalist calls 'mere' words, that is, general types and would-bes. The nominalist is right in saying that they are substantially of the nature of words; but his 'mere' reveals a complete misunderstanding of what our everyday world consists of" (Peirce CP, 8.191).

19 Explored to some degree in (Olen 2016).

20 I endeavored to argue this in more depth at the end of Legg (2017).

21 At some points in Having the World in View McDowell does gesture towards understanding this, e.g., in Chapter 2, "The Logical Form of an Intuition," but I would argue that he doesn't thoroughly integrate it.

22 Levine (2007) also ably defends the compatibility of these two positions, with specific reference to Sellars's philosophy of perception, although I take issue with his interpretation of Sellars's sensations as able to be 'led into' the space of reasons. 


\section{Catherine Legg}

\section{References}

Bermúdez, José Luis. 1995. 'Nonconceptual Content: From Perceptual Experience to Subpersonal Computational States'. Mind and Language, 10, 4: 333-69.

Brandom, Robert B. 1994. Making It Explicit. Cambridge, MA: Harvard University Press.

Brandom, Robert B. 2000. Articulating Reasons: An Introduction to Inferentialism. Cambridge, MA: Harvard University Press.

Brandom, Robert B. 2002. 'The Centrality of Sellars' Two-Ply Account of Observation to the Arguments of "Empiricism and the Philosophy of Mind"'. In Tales of the Mighty Dead, 523-53. Cambridge, MA: Harvard University Press.

Brandom, Robert B. 2007. 'Inferentialism and Some of Its Challenges'. Philosophy and Phenomenological Research, 74, 3: 651-76.

DeVries, Willem A. 2006. 'McDowell, Sellars, and Sense Impressions'. European Journal of Philosophy, 14, 2: 182-201.

DeVries, Willem A. and Coates, Paul. 2009. 'Brandom's Two-Ply Error'. In Empiricism, Perceptual Knowledge, Normativity and Realism: Essays on the Anniversary of "Empiricism and the Philosophy of Mind". Edited by W.A. deVries, 131-45. Oxford: Oxford University Press.

Forman, David. 2007. 'Learning and the Necessity of Non-Conceptual Content in Sellars's "Empiricism and the Philosophy of Mind"'. In The Self-Correcting Enterprise: Essays on Wilfred Sellars. Edited by Michael P. Wolf and Mark Norris Lance, 115-45. Poznan Studies in the Philosophy of the Sciences and the Humanities. Vol. 92. New York: Rodopi.

Haack, Susan. 1994. 'How the Critical Common-Sensist Sees Things'. Histoire Épistémologie Langage, 16, 1: 9-34.

Jackson, Frank. 1982. 'Epiphenomenal Qualia'. Philosophical Quarterly, 32, 127: 127-36.

Jones, Karen. 2008. 'How to Change the Past'. In Practical Identity and Narrative Agency. Edited by C. Mackenzie and K. Atkins, 269-88. London: Routledge.

Koopman, Colin. 2007. 'Language is a Form of Experience: Reconciling Classical Pragmatism and Neopragmatism'. Transactions of the Charles S. Peirce Society, 43, 4: 694-727.

Legg, Catherine. 2008. 'Making It Explicit and Clear: From "Strong" to "Hyper-" Inferentialism in Brandom and Peirce'. Metaphilosophy, 39, 1: 105-23.

Legg, Catherine. 2014. “"Things Unreasonably Compulsory”: A Peircean Challenge to a Human Theory of Perception: Particularly with Respect to Perceiving Necessary Truths'. Cognitio, 15, 1: 89-112.

Legg, Catherine. 2017. 'Idealism Operationalized: How Peirce's Pragmatism Can Help Explicate and Motivate the Possibly Surprising Idea of Reality as Representational'. In From Icons to Logic: Peirce on Perception and Reasoning. Edited by K. Hull and R.K. Atkins, 40-53. London: Routledge.

Levine, Steven. 2007. 'Sellars' Critical Direct Realism 1'. International Journal of Philosophical Studies, 15, 1: 53-76.

Levine, Steven. 2012. 'Brandom's Pragmatism'. Transactions of the Charles S. Peirce Society, 48, 2: 125-40.

Macbeth, Danielle. 2009. 'Un'antinomia del giudizio empirico: Brandom e McDowell'. In Lo Spazio Sociale della Ragione: Da Hegel in Avanti. Edited by L. Ruggiu and I. Testa, 343-60. Milan: Mimesis. 
Massecar, Aaron. 2012. 'Peirce's Interesting Associations'. Transactions of the Charles S. Peirce Society: A Quarterly Journal in American Philosophy, 48, 2: 191-208.

McDowell, John. 1994. 'The Content of Perceptual Experience'. The Philosophical Quarterly, 44, 175: 190-205.

McDowell, John. 1994. Mind and World. Cambridge, MA: Harvard University Press.

McDowell, John. 1997. 'Brandom on Representation and Inference'. Philosophy and Phenomenological Research, 57, 1: 157-62.

McDowell, John. 2005. 'Motivating Inferentialism: Comments on Making It Explicit (Ch. 2)'. Pragmatics and Cognition, 13, 1: 121-40.

McDowell, John. 2009. Having the World in View: Essays on Kant, Hegel, and Sellars. Cambridge, MA: Harvard University Press.Olen, Peter. 2016. Wilfrid Sellars and the Foundations of Normativity. London: Palgrave Macmillan.

Peacocke, Christopher. 1992. A Study of Concepts. Cambridge, MA: MIT Press.

Peacocke, Christopher. 1998. 'Nonconceptual Content Defended'. Philosophy and Phenomenological Research, 58, 2: 381-8.

Redding, Paul. 2014. 'An Hegelian Solution to a Tangle of Problems Facing Brandom's Analytic Pragmatism'. British Journal for the History of Philosophy, 23, 4: 657-80.

Redding, Paul. 2017. 'Hegel and Sellars "Myth of Jones": Can Sellars Have More in Common with Hegel Than Rorty and Brandom Suggest?' In Wilfrid Sellars, Idealism and Realism. Edited by P.J. Reider, 41-58. London: Bloomsbury.

Rosenthal, Sandra. 2001. 'The Percipuum and the Issue of Foundations'. www. digitalpeirce.fee.unicamp.br/perros.htm.

Sant'Anna, André. Forthcoming. 'Perception Pragmatized: A Pragmatic Reconciliation of Representationalism and Relationalism'. Philosophia.

Sellars, Wilfrid (EPM). 1956/1997. Empiricism and the Philosophy of Mind. With an Introduction by Richard Rorty and a Study Guide by Robert Brandom. Cambridge, MA: Harvard University Press.

Sellars, Wilfrid (SPR). 1963. Science, Perception and Reality. London: Routledge.

Sellars, Wilfrid. 1982. 'Sensa or Sensings: Reflections on the Ontology of Perception'. Philosophical Studies, 41, 1: 83-114.

Speaks, Jeff. 2005. 'Is There a Problem About Nonconceptual Content?' The Philosophical Review, 114, 3: 359-98.

Travis, Charles S. 2004. 'The Silence of the Senses'. Mind, 113, 449: 57-94. 